\title{
Molecular detection and characterization of nodavirus in several marine fish species from the northeastern Atlantic
}

\author{
N. Gagné ${ }^{1, *}$, S. C. Johnson ${ }^{2}$, M. Cook-Versloot ${ }^{3}$, A. M. MacKinnon ${ }^{1}$, G. Olivier ${ }^{1}$ \\ ${ }^{1}$ Fisheries and Oceans Canada, 343 University Ave, Moncton, New Brunswick E1C 9B6, Canada \\ ${ }^{2}$ National Research Council, 1411 Oxford St, Halifax, Nova Scotia B3H 3Z1, Canada \\ ${ }^{3}$ Research and Productivity Council, 921 College Hill Rd, Fredericton, New Brunswick E3B 6Z9, Canada
}

\begin{abstract}
Nodaviruses (NNV) are responsible for causing disease outbreaks mainly in hatcheryreared larvae and juveniles of a wide variety of fishes throughout the world. This disease has seriously limited the culture of marine fishes over the last decade. In the Atlantic provinces of Canada, disease caused by a nodavirus was first reported in juvenile Atlantic cod being reared in Nova Scotia, in 1999. More recently, disease outbreaks caused by nodavirus have been identified in hatcheryreared Atlantic cod and haddock in Newfoundland and New Brunswick, respectively, and along the east coast of the USA. The presence of NNV in wild Atlantic cod adults and wild winter flounder has also been reported. Nodaviruses were isolated from cultured Atlantic cod and haddock, as well as from wild winter flounder from a variety of geographical localities, and their virus coat (capsid) protein genes were partially sequenced. An analysis of the data indicates that all of the nodaviruses isolated from eastern North America were closely related to one another, but that they were distinct from the European isolates already sequenced. Regardless of host species, isolates from close geographical localities were more similar than those from distant geographical areas. At the protein level, differences in coat protein sequences were seen only for strains isolated from Atlantic cod originating from Newfoundland. Our results suggest that NNV may have been present in the Atlantic off Canada and on the east coast of the USA for some time, and has evolved to form a monophyletic group, distinct from other isolates found in cold-water species. Non-lethal methods for detection of NNV are necessary to develop management strategies for this disease, and would be an asset to diagnosticians and producers. Based on the results of this study, new primers were designed and developed for an improved RT-PCR assay able to detect North Atlantic nodaviruses in ovarian fluids, eggs and other tissues. The application of this test to field samples is discussed.
\end{abstract}

KEY WORDS: Nodaviruses $\cdot$ RT-PCR $\cdot$ Phylogenetic analysis $\cdot$ Atlantic cod $\cdot$ Haddock

\section{INTRODUCTION}

Fish nodaviruses (NNV) belonging to the Betanodaviridae have been reported to cause disease in approximately 40 species of marine finfish in aquaculture worldwide. The disease is known either as viral nervous necrosis (VNN), viral encephalopathy and retinopathy (VER), or fish encephalitis. VNN outbreaks result in high mortalities mainly in hatcheryreared larvae and juveniles, although adults can also be affected (reviewed in Munday et al. 2002). In North America, outbreaks of disease caused by nodavirus have been reported in hatchery-reared Atlantic cod (Gadus morhua) and/or haddock (Melanogrammus aeglefinus) in Newfoundland, Nova Scotia, New Brunswick and along the east coast of the USA (Johnson et al. 2002, N. King pers. comm). These disease outbreaks have resulted in high levels of morbidity and mortality. The presence of nodavirus in wild adult Atlantic cod and wild adult winter floun- 
der (Pleuronectes americanus) has been reported from Atlantic Canada (Barker et al. 2002, Cusack 2002). Nodavirus infection has been reported in cultured juveniles of Atlantic cod from the UK, with low mortality rates (approximately $2 \%$ ) observed over a 3-mo period (Starkey et al. 2001).

Nodaviruses are small non-enveloped viruses, and their genome consists of 2 sense RNA strands. RNA1 $(3.1 \mathrm{~kb})$ of striped jack NNV encodes a putative RNAdependent RNA polymerase (RdRp) and RNA2 (1.4 kb) encodes the capsid protein precursor (Mori et al. 1992). To date, comparisons between the nucleotide sequences of a variable region of the capsid protein referred to as T4 (Nishizawa et al. 1994) have led to the division of the genus Betanodavirus into 7 type species: barfin flounder nervous necrosis virus (BFNNV), Dicentrarchus labrax encephalitis virus (DIEV), Japanese flounder nervous necrosis virus (JFNNV), Lates calcarifer encephalitis virus (LcEV), redspotted grouper nervous necrosis virus (RGNNV), striped jack nervous necrosis virus (SJNNV) and tiger puffer nervous necrosis virus (TPNNV) (Van Regenmortel 2000).

In order to develop appropriate disease management strategies for this disease we need to (1) determine whether the NNV isolates obtained from different host

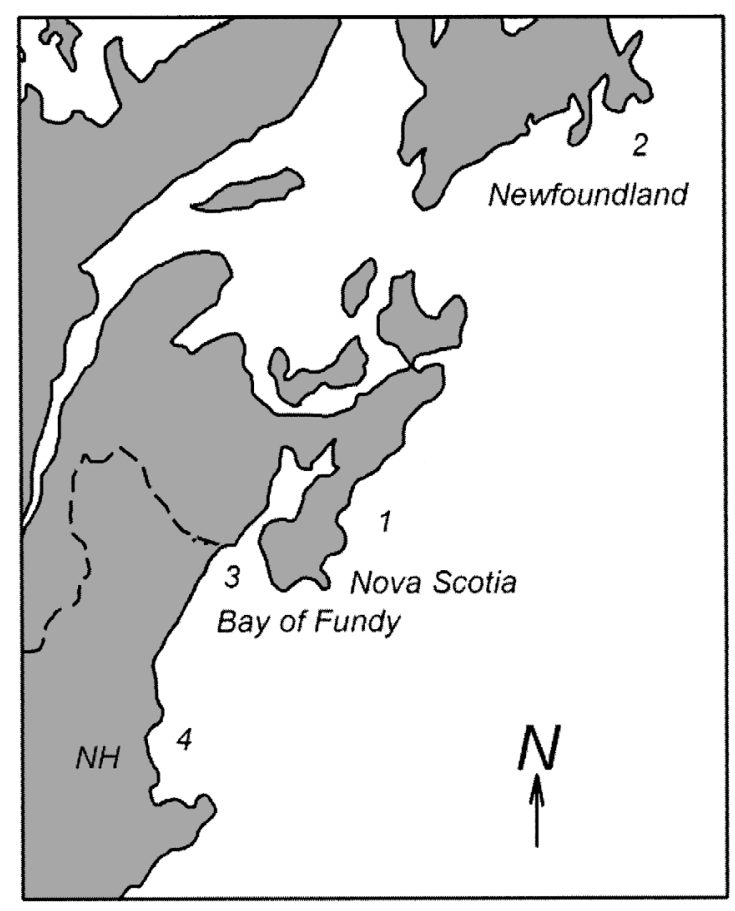

Fig. 1. Approximate location of fish aquaculture facilities or fish capture sites where nodaviruses were isolated. 1: Atlantic cod isolates from Nova Scotia; 2: Atlantic cod isolates from Newfoundland; 3: wild winter flounder and haddock isolates from New Brunswick; 4: Atlantic cod isolates from New Hampshire species are the same, (2) evaluate and validate methods for NNV screening and disease diagnosis, and (3) develop non-lethal methods for screening broodstock. With respect to screening and disease diagnosis, reverse-transcriptase polymerase chain reaction (RTPCR) assays for NNV can be conveniently used to check the health status of animals by testing reproductive material, eggs, larvae and juveniles at all stages of production (Dalla Valle et al. 2000). Although RT-PCR methods for the detection of nodaviruses are available (Nishizawa et al. 1994, Grotmol et al. 2000), their sensitivity depends greatly on having primers that are designed to complement the NNV isolates of interest.

In this study we partially sequenced the coat protein gene of NNV isolates from eastern Canada and the northeastern USA to determine the phylogenetic relationship between these isolates and isolates from other host species and geographical regions. Based on the results, RT-PCR primers were designed and used to optimize an RT-PCR assay for these isolates.

\section{MATERIALS AND METHODS}

NNV isolates. Isolates of NNV were obtained from disease outbreaks and surveys of wild fish from a variety of locations in eastern Canada and the northeastern USA (Fig. 1). NNV isolates from the 2002 outbreak affecting Atlantic cod in Newfoundland (NL) were a kind gift of Dr C. Yason, while an isolate from the 2002 outbreak affecting Atlantic cod in New Hampshire was a kind gift of D. Bouchard. The Atlantic cod NNV isolates from 1999 and 2002 were isolated by the Research and Productivity Council, Fredericton, NB (Johnson et al. 2002). NNV from a wild winter flounder was isolated by the Department of Fisheries and Oceans, Fish Health Unit, Moncton, NB (Barker et al. 2002). We also isolated NNV from brain and eye tissues of dead and moribund juvenile haddock that were collected during a VNN outbreak that occurred at the St-Andrews Biological Station (SABS) in New Brunswick in 2002. In this instance we also took brain and eye tissues from individual haddock immediately after necropsy and placed them into an RNA protection medium (RNALater, Ambion). These tissues were stored at $-20^{\circ} \mathrm{C}$ until RNA extraction. All isolates were obtained using the methods outlined below for haddock tissues and were kept at $-70^{\circ} \mathrm{C}$ for long-term storage.

Cell culture of nodavirus. Immediately after necropsy, haddock brain and eye tissues were processed for viral culture either individually or as pools of tissues from up to 5 individuals. Briefly, tissues were homogenized in a dilution of 1:50 (w/v) in Hanks' balanced salt solution (HBSS, pH 7.6) using a stomacher 
(Seward Laboratory). Homogenates were centrifuged at $2500 \times g$ for $15 \mathrm{~min}$ at $4^{\circ} \mathrm{C}$, and resulting supernatants were aseptically filtered through membranes $(0.45 \mu \mathrm{m}$ pore diameter). Filtrates $(0.1 \mathrm{ml})$ were applied in duplicate to 24-well plates containing striped snakehead-1 (SSN-1) cells (ECACC No. 96082808) and cultured at $25^{\circ} \mathrm{C}$ for a minimum of $28 \mathrm{~d}$. Cell cultures showing a cytopathic effect (CPE) were subcultured, and the presence of NNV was confirmed by RT-PCR following the method described below.

Isolates of NNV obtained from other laboratories were re-inoculated onto SSN-1 cells and cultured at $25^{\circ} \mathrm{C}$ for a minimum of $7 \mathrm{~d}$ prior to RNA isolation.

RNA extraction and RT-PCR. RT-PCR was used to amplify coat protein genes of NNV from haddock tissues and from cell culture lysates. Total RNA was isolated from cell culture lysates and RNALater ${ }^{\circledR}$ preserved eye and brain tissues using TRI Reagent ${ }^{\mathrm{TM}}$ (Molecular Research Center) following the manufacturer's instructions. Resulting total RNA samples were redissolved in $20 \mu \mathrm{l}$ each of sterile $\mathrm{H}_{2} \mathrm{O}$ containing RNase inhibitor. Reverse transcription primed with random hexamers was done with a RevertAid ${ }^{\mathrm{TM}}$ first strand cDNA synthesis kit (MBI Fermentas) using up to $5 \mu \mathrm{g}$ of RNA and following manufacturer's instructions. PCR amplifications were done with a AmpliTaq Gold ${ }^{\circledR}$ PCR Master Mix (Applied Biosystems) in $25 \mu$ l volumes containing $2 \mu \mathrm{l}$ of cDNA, $0.4 \mu \mathrm{M}$ of each primer, $1 \mu \mathrm{l}$ of BSA $1 \%$ and $2.5 \mathrm{mM} \mathrm{MgCl}_{2}$. PCR conditions were $94^{\circ} \mathrm{C}$ for 4 min (initial denaturation), followed by 10 cycles of $94^{\circ} \mathrm{C}$ for $30 \mathrm{~s}+60^{\circ} \mathrm{C}\left(-1^{\circ} \mathrm{C}\right.$ per cycle) for $30 \mathrm{~s}$ $+72^{\circ} \mathrm{C}$ for $90 \mathrm{~s}$ and then 35 cycles of $94^{\circ} \mathrm{C}$ for $30 \mathrm{~s}+$ $50^{\circ} \mathrm{C}$ for $30 \mathrm{~s}+72^{\circ} \mathrm{C}$ for $90 \mathrm{~s}$ and a final hold at $72^{\circ} \mathrm{C}$ for 5 min. Amplification products were resolved on $1.5 \%$ agarose gels (Roche Diagnostics), using a 100-bp ladder as a marker (MBI Fermentas).

Several primers designed to amplify NNV coat protein sequences were used in this study (Table 1). Primers 313F and 591R were used to identify NNV in haddock tissues and cell cultures, as well as in RT-PCR optimization studies. Primer 495R was designed for use in RT-PCR optimization studies. Primers 1322R, NVHF and NVH-R2 were designed to amplify larger regions of the coat protein sequence for use in phylogenetic studies.

RT-PCR optimization. The sensitivity of RT-PCR using either primers $313 \mathrm{~F} / 591 \mathrm{R}$ or $313 \mathrm{~F} / 495 \mathrm{R}$ was compared using the PCR conditions outlined above. A semi-nested RT-PCR assay was also evaluated, using primers 313F/591R for the first round of PCR amplifica- tion and 313F/495R for the second round. PCR conditions for the nested reactions were as described above, except that the number of cycles after the initial touchdown cycles was reduced to 20 for the first PCR round and 30 for the second PCR round. From the first PCR amplification, $1 \mu \mathrm{l}$ of the product was used as template for the second PCR round.

The effect of RNA denaturation at $95^{\circ} \mathrm{C}$ for $5 \mathrm{~min}$ and at $70^{\circ} \mathrm{C}$ for $10 \mathrm{~min}$ was also compared to evaluate the effect of denaturation temperature on the sensitivity of RT-PCR detection. Sensitivity was evaluated on serial dilutions of NNV cultures. Briefly, a NNV culture was diluted 1/10 in PBS before extracting RNA as outlined above. RNA denaturation was done either at $70^{\circ} \mathrm{C}$ or $95^{\circ} \mathrm{C}$ before reverse transcription. PCR amplifications of the NNV serial dilutions were done using either primers $313 \mathrm{~F} / 591 \mathrm{R}$ or $313 \mathrm{~F} / 495 \mathrm{R}$ and the method described above.

As the tissue type may be a limiting factor in RTPCR, we tested our optimized RT-PCR procedure on samples of haddock eggs that were spiked with virus. Haddock eggs ( $1 \mathrm{ml}$ volume) were mixed with $1 \mathrm{ml}$ of a 1:1000 dilution of NNV-positive cell lysates and left at room temperature for $30 \mathrm{~min}$. The eggs were then washed twice with 8 vol of PBS, and RNA was extracted from the eggs as described previously, followed by RT-PCR analysis using primers 313F and 591R.

Partial sequencing of the coat protein gene (RNA2). Partial coat protein nucleotide sequences were obtained from RT-PCR products amplified using primer sets 313F/1322R or NVHF/NVH-R2 and conditions as described above. Internal primers were also used for sequencing these fragments. RT-PCR products were either sequenced directly or after cloning with TOPO TA cloning $\mathrm{kit}^{\circledR}$ (Invitrogen) following manufacturer's instructions.

Each isolate was sequenced at least twice, and on both strands. Sequencing was done either on an ABI 373 or an ABI 3100 Automated Sequencer using 
PRISM Big Dye Terminator (PE Applied Biosystems) or on an ALFexpress II using Thermo Sequenase Cy5 dye terminators (Amersham Biosciences).

Phylogenetic analysis. Sequences were assembled using Sequencher (Gene Codes) and GeneDoc (www.psc.edu/biomed/genedoc). A BLAST similarity search (Altschul et al. 1990) for significant homologous sequences was done against GenBank (National Center for Biotechnology Information) using the NNV sequence of the Newfoundland Atlantic cod isolate. Other NNV coat protein nucleotide sequences were selected for phylogenetic analysis, and are listed in Table 2. Multiple alignments of nucleotide and deduced amino acid sequences were performed using ClustalX (1.81) (Thompson et al. 1997). Phylogenetic analysis was conducted with DNAML from the PHYLIP package (3.6a3) (Felsenstein 1997) and with TREE-PUZZLE (5.0) (Schmidt et al. 2002). Tree branches supporting values of $70 \%$ and more can be considered reliable. TreeView version 1.6.6 (Page 1996) was used to view the trees.

\section{RESULTS}

\section{Isolation and confirmation of NNV in haddock}

In 2002, juvenile haddock ( 3 to 6 mo old) that were being held at SABS began showing signs of disease similar to those reported for other species with VNN. A total of 164 juvenile haddock were submitted for disease diagnosis. Of these, 90 samples were examined by virus culture, using both individual and pooled samples of brain and eye tissue homogenates. RT-PCR was conducted using primers $313 \mathrm{~F}$ and 591R to confirm the presence of NNV in CPE-positive cell cultures. In total, 74 (82\%) out of the 90 samples were positive for NNV by culture, and all were confirmed as NNV positive by RT-PCR. Using the primers $313 \mathrm{~F}$ and 591R, eye and brain tissues from these individual fish were also directly tested by RTPCR. Of the 146 samples of brain and eye tissues examined, 104 (71.5\%) were positive for NNV. For 61 individuals, for whom we had both cell-culture and RT-PCR data, we compared the results obtained by these 2 meth-

Table 2. Nodavirus isolates used for phylogenetic analysis, host species, country and location, year of isolation, Accession No. or reference. ? indicates that the information is uncertain or unknown

\begin{tabular}{|c|c|c|c|c|}
\hline Isolate & Host species & Country & Year & $\begin{array}{l}\text { Accession No. } \\
\text { or source }\end{array}$ \\
\hline Cod02ac3 & Atlantic cod Gadus morhua & USA (New Hampshire) & 2002 & Present study ${ }^{\mathrm{a}}$ \\
\hline Wf00ac & Winter flounder Pseudopleuronectes americanus & Atl. Canada (Bay of Fundy) & 2000 & Present study ${ }^{\mathrm{a}}$ \\
\hline Cod99ac & Atlantic cod Gadus morhua & Atl. Canada (Nova Scotia) & 1999 & AF445800 \\
\hline Cod02ac & Atlantic cod Gadus morhua & Atl. Canada (Nova Scotia) & 2002 & AY547548 \\
\hline Cod02ac2 & Atlantic cod Gadus morhua & Atl. Canada, New Foundland & 2002 & AY547547 \\
\hline Had02ac1 & Haddock Melanogrammus aeglefinus & Atl. Canada (Bay of Fundy) & 2002 & Present study ${ }^{\mathrm{a}}$ \\
\hline Had02ac2 & Haddock Melanogrammus aeglefinus & Atl. Canada (Bay of Fundy) & 2002 & AY547549 \\
\hline Had02ac3 & Haddock Melanogrammus aeglefinus & Atl. Canada (Bay of Fundy) & 2002 & Present study ${ }^{\mathrm{a}}$ \\
\hline HhNNV1 & Atlantic halibut Hippoglossus hippoglossus & Norway & 1999 & $\mathrm{AJ} 245641$ \\
\hline HhNNV2 & Atlantic halibut Hippoglossus hippoglossus & Norway & 1999 & AF160473 \\
\hline BF93hok & Barfin flounder Verasper moseri & Japan & 1993 & D38635 \\
\hline SJOri & Striped jack Pseudocaranx dentex & Japan & 1991 & D30814 \\
\hline Dlev-Fr & European seabass Dicentrarchus labrax & France & 1997 & U39876 \\
\hline TP93kag & Tiger puffer Takifugu rupripes & Japan & 1993 & D38637 \\
\hline RG91tok & Redspotted grouper Epinephelus akaara & Japan & 1991 & D38636 \\
\hline Jf93Hir & Japanese flounder Paralichthys olivaceous & Japan & 1993 & D38527 \\
\hline Gup & Guppy Poecilia reticulata & Singapore? & $?$ & AF499774 \\
\hline DgNNV & Dragon Epinephelus lanceolatus & Taiwan & $?$ & AF245004 \\
\hline MR & Malabaricus Epinephelus malabaricus & Taiwan & $?$ & AF245003 \\
\hline Uc96Ita1 & Shi drum Umbrina cirrosa & Italy & 1996 & AJ277811 \\
\hline Dl-th1 & European seabass Dicentrarchus labrax & Thailand & $?$ & AF175518 \\
\hline Dl-8 & European seabass Dicentrarchus labrax & Italy & 1998 & AJ277810 \\
\hline YG-Tw & Yellow grouper Epinephelus awoara & Taiwan? & $?$ & AF283554 \\
\hline JF-2 & Japanese flounder Paralichthys olivaceous & Japan? & $?$ & AB045980 \\
\hline OsG-Ch & Orange-spotted grouper Epinephelus coioides & China & $?$ & AF534998 \\
\hline Dlev-Gr & European seabass Dicentrarchus labrax & Greece & 1997 & Y08700 \\
\hline GGNNV & Greasy grouper Epinephelus tauvina & Singapore & $2000 ?$ & AF318942 \\
\hline Ba94Aus & Barramundi Lates calcarifer & Australia & 1994 & $\begin{array}{l}\text { Nishizawa et al. } \\
\text { (1997) }\end{array}$ \\
\hline BBV & Black beetle virus & $?$ & $?$ & NC 002037 \\
\hline
\end{tabular}


ods. Only 1 sample that was positive by cell culture was not positive by RT-PCR, and 7 samples found to be positive by RT-PCR were negative by cell culture.

\section{RT-PCR optimization}

We initially evaluated a semi-nested PCR assay for the detection of NNV using primers 313F/591R for the first round of PCR amplification and 313F/495R for the second round, as this technique is usually more sensitive than a single PCR (Dalla Valle et al. 2000). The analysis of individual pairs of primers on a selected set of samples showed that a single PCR with primers $313 \mathrm{~F}$ and 495R was equally sensitive to the nested assay (results not shown), without the added risks of contamination caused by the additional steps needed during the nested PCR assay.

Denaturation of RNA prior to reverse transcription at $95^{\circ} \mathrm{C}$ improved the sensitivity of the RT-PCR assay ( 2 to $3 \log$ ) when compared to the manufacturer's suggested temperature of $70^{\circ} \mathrm{C}$. The primer sensitivity and specificity was tested using serial dilutions of cell lysates. We could detect on average the equivalent of 10 to $100 \mathrm{TCID}_{50}$ (tissue culture infective dose $50 \%$ ) of viral particles using primers $313 \mathrm{~F} / 495 \mathrm{R}$ and a temperature of $95^{\circ} \mathrm{C}$ for RNA denaturation, while $1 \times 10^{3}$ to $1 \times 10^{4}$ $\mathrm{TCID}_{50}$ of viral particles were detected with primers 313F/591R at this temperature (not shown). Haddock eggs exposed to NNV were also consistently found positive with the optimized RT-PCR assay or with primers 313F/591R (results not shown).

\section{Partial coat protein gene sequences}

We obtained partial coat protein gene sequences for a total of 13 isolates of NNV from haddock, winter flounder and Atlantic cod. For most isolates, the sequences were obtained independently from 2 laboratories, and both strands were sequenced in order to obtain accurate data. The haddock isolate was passed several times in culture and injected into naïve haddock. The sequence obtained after these passages was identical to the initial sequence. Almost full-length sequences of this gene from haddock NNV, Atlantic cod NNV from Nova Scotia and Atlantic cod NNV from Newfoundland have been deposited in GenBank under the Accession Nos. AY547547 to AY547549.

Comparison of the nucleotide sequence of a 925-bp region (position 446 to 1047 of SJOri [striped jack, Pseudocaranx dentex], GenBank Accession No. D30814) indicated a 99\% nucleotide homology between the isolates obtained from Nova Scotia, New Brunswick and New Hampshire regardless of host species. There were no differences in the deduced amino acid sequences between these isolates (Fig. 2). Three Atlantic cod isolates from Newfoundland were sequenced and gave identical results. Comparison of these isolates with the other isolates from this study indicated a 95\% nucleotide homology and a 98\% amino acid homology. This amounts to 5 amino acid substitutions within the T4 region of the Newfoundland isolate (Fig. 2); 4 of these substitutions resulted in a replacement with threonine.

The closest sequence retrieved using BLAST similarity search on GenBank was from Atlantic halibut NNV from Norway (Accession No. AJ245641), with a nucleotide and amino acid homology of 93 and $96 \%$, respectively, compared to the Atlantic cod isolates.

By comparison to other fish nodaviruses, eastern North American isolates share a sequence very rich in basic amino acids at the $\mathrm{N}$ terminus, with 9 arginines and 6 lysines among the first 50 amino acids. There is also high conservation of the non-translated 3 ' portion of RNA2, which is also observed in other NNV sequences.

\section{Phylogenetic tree inference}

Maximum-likelihood analyses using the nucleotide sequences of the $\mathrm{T} 4$ region of the coat protein gene were conducted to infer the phylogenetic relationship of NNV isolates from the North Atlantic (Fig. 3). All of the isolates reported in this study form a monophyletic group that we have referred to as the Atlantic cod NNV clade (ACNNV). Within the group, the isolate from Atlantic cod in Newfoundland (Cod02ac2) separates earlier, suggesting that it is an ancestral form when compared to the rest of the group. The isolates from the Bay of Fundy area (region 3 in Fig. 1) are all closely related, and the isolate from New Hampshire is grouped with them, although the support value is somewhat low. The Atlantic cod isolates from southern Nova Scotia are closely related, although they were recovered 3 yr apart. One of the haddock isolates from the Bay of Fundy is grouped with the Atlantic cod isolates from Nova Scotia, but the grouping is not well supported.

The barfin flounder clade (BFNNV) is a sister group of the ACNNV (Fig. 3). Using an alphanodavirus (black beetle virus or BBV) as an outgroup indicated that the root of the inferred tree is located at a point that separates NNV isolated from cold-water hosts (BFNNV and ACNNV) from NNV isolated from hosts in more temperate or tropical waters (Fig. 3). Alternative inference methods were used to examine the phylogenetic relationship, and these methods produced similar results (results not shown). 
Cod0 2ac2 : GGYVAGF LP DP TD SDHT FDAI QA TR GA VVAKWWES RT IR PQ YARA LLWT SV GKEQRL TS PG RL IL LCVG NN TDVVNV SV LC RW SVRL SV PS LE TPEDTEA

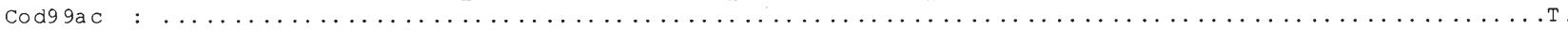

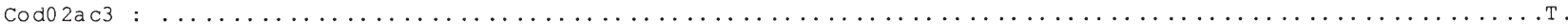

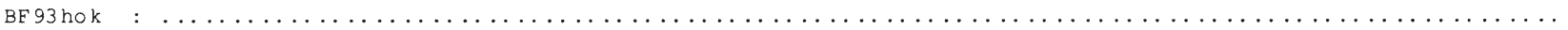

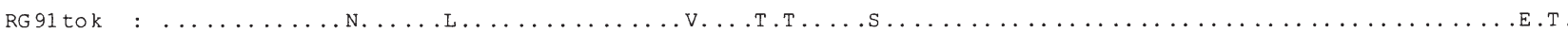

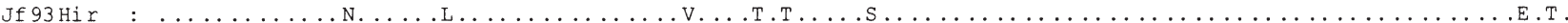

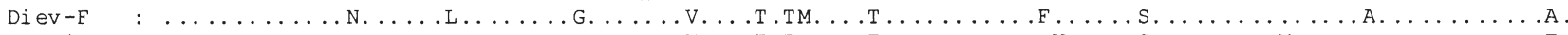

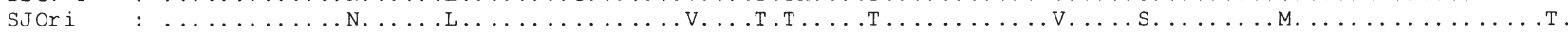

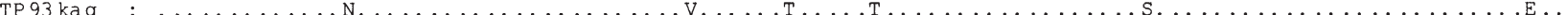

120

140

160

180

Co d0 2a c2 : P IL SL GP LYND SL --AVND FK SI LL GA TQ LD IA PE GAVY TL DR PL SI DY NL GT GDVD RA VY WH VK KV AG NA GT PA GW FH WG LW DN FN KT FT QG VA YY SD $Q$

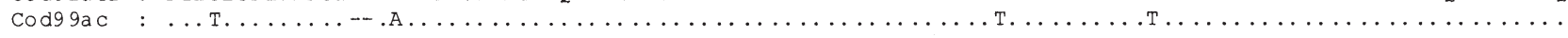

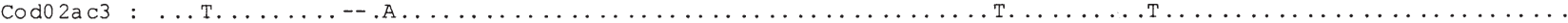

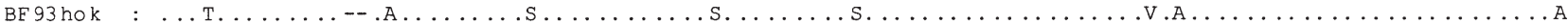

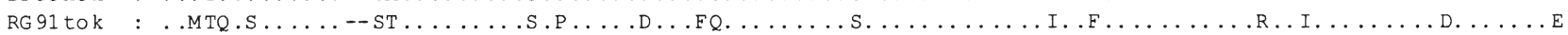

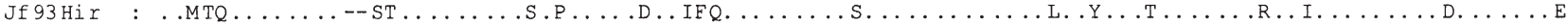
Diev-F SJOr $i$ TP $93 \mathrm{kag}$ $\ldots \ldots \ldots \ldots$. . . . . . . . . . . . . . . .

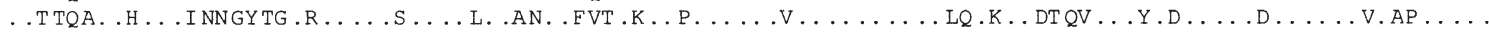

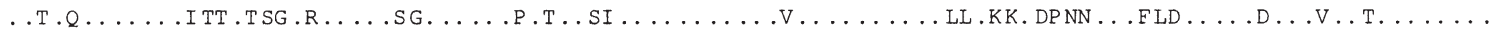

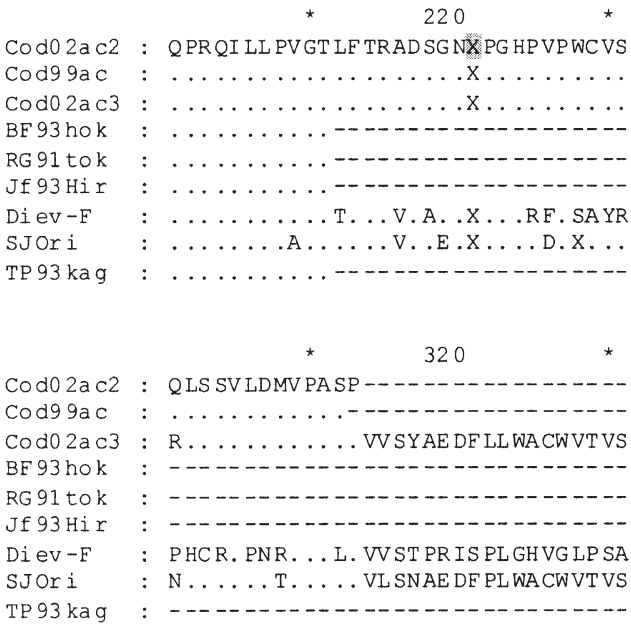

\section{DISCUSSION}

Nodaviruses are well recognized as important pathogens of marine fish, with disease outbreaks caused by these viruses reported as early as 1990 (Yoshikoshi \& Inoue 1990). The first report of NNV on the Atlantic coast of North America was from a disease outbreak that occurred in 1999 in hatchery-reared Atlantic cod in Nova Scotia (Johnson et al. 2002). Shortly following that report, NNV was isolated from a wild-caught winter flounder from Passamaquoddy Bay, NB, Canada (Barker et al. 2002). Since those reports, outbreaks of disease caused by NNV have been reported from 4 different regions of eastern Canada and the northeastern United States, i.e. in Atlantic cod in Nova Scotia and Newfoundland in 2002 and in New Hampshire in 2001/2002, as well as in haddock in New Brunswick in 2002. Disease caused by nodavirus is recognized as a potential threat to the successful development of Atlantic cod and haddock aquaculture in North America. Therefore, the develop-
Fig. 2. Multiple alignment of the deduced partial coat protein amino acid sequence of North Atlantic NNV isolates and other type species. Open reading frame stops at position 221 on the figure. The deduced amino acid sequence of the isolates from Nova Scotia and New Brunswick (not shown) are identical to isolate Cod99ac. X: stop codons; dashes indicate gaps in the alignment or end of sequence information available

ment of disease management strategies and improved diagnostic tools have been identified as priorities to support the successful large-scale rearing of Atlantic cod and haddock.

The ability to manage disease requires the development and validation of sensitive diagnostic tools, which in the case of NNV include RT-PCR. With RT$\mathrm{PCR}$, the presence of sequence mismatches between primers and target may result in poor amplification or even the absence thereof (Nishizawa et al. 1996, Thiery et al. 1999). Although several RT-PCR primers for NNV have been published (Nishizawa et al. 1994, Dalla Valle et al. 2000), it is not certain that they perform optimally with new local isolates from Atlantic cod and haddock (Johnson et al. 2002). Since the success and sensitivity of RT-PCR relies heavily on the primers used, our approach was to design new primers based on all available NNV coat protein sequences, but specifically matching North American isolates. Our primer $313 \mathrm{~F}$ perfectly matches the sequences of all the NNV isolates used in the phylo- 


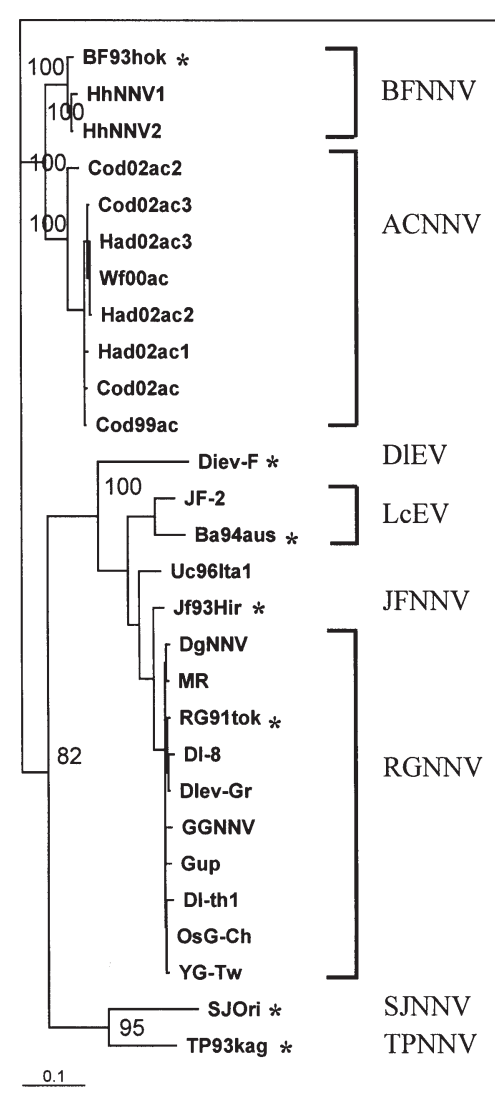

Fig. 3. Consensus tree constructed with TREE-PUZZLE 5.0 by the maximum likelihood method, and inferred with 1000 quartet puzzling steps and maximum likelihood branch lengths. Black beetle virus (BBV) was used as outgroup. The (*) indicates NNV type species of each clade. The bar equals 0.1 nucleotide replacement. Some support values of branch nodes are not indicated for clarity

genetic analysis and represents a good 'universal NNV primer'. The sequence of primer 591R matches most of them, with at most 3 nucleotide differences with SJOri (Accession No. D30814). This primer is the reverse complement of primer F2 (Nishizawa et al. 1994), with the exception of 2 nucleotides that were substituted to better match known NNV isolates. It also overlaps forward primer AH95-F1 (Grotmol et al. 2000). The assay designed by Grotmol et al. (2000) could also be useful for the detection of cold-water strains of NNV, but the reverse primer is probably not suitable for all strains of NNV.

Using primers 313F/591R, we detected nodavirus RNA in eye and brain tissues of haddock (146 samples, $71.5 \%$ positive results). Primer 495R matches the sequences of all isolates within the barfin flounder clade, as well as the sequences of isolates described in the present study. However, this primer is not suitable for use with the other isolates of NNV, due to the pres- ence of 3 ' mismatches. None of the described RT-PCR protocols target the 3 ' non-coding portion of RNA2. This region of RNA2 appears to be well conserved between species, and it may be possible to design primers in this area suitable for all NNV species. Unfortunately, this region has not been sequenced for the majority of NNV species.

Using primer pairs 313F/591R and 313F/495R, we optimized a RT-PCR protocol for identification of Atlantic cod and haddock NNV in tissues and cell cultures. We were able to improve the sensitivity of the assay by increasing the temperature of RNA denaturation from 70 to $95^{\circ} \mathrm{C}$, although RNA is very labile at this high temperature. This difference might be peculiar to viruses such as NNV, and could be caused by strong RNA secondary structure.

In this paper we have described the partial coat protein gene sequences from a variety of nodavirus isolates obtained from Atlantic cod, haddock and winter flounder collected along the North Atlantic coast of North America. This is also the first report on NNV isolated from cultured haddock. Although the deduced coat protein sequences of all the isolates were highly similar, there are differences within the sequences that appear to be related more to the geographical origin of the virus rather than to the host species from which it was isolated. Isolates from fish obtained from $\mathrm{New}$ Brunswick, New Hampshire and Nova Scotia had highly similar nucleotide sequences and no differences in their deduced amino acid sequences, regardless of host. However, the sequence obtained for the Atlantic cod isolate from Newfoundland had a greater number of nucleotide differences, resulting in the variation of 5 amino acids compared to other isolates; 4 of these substitutions resulted in a replacement with threonine, which might indicate a selective process. The lack of deduced amino acid sequence differences amongst the isolates collected from hosts caught in New Brunswick, New Hampshire and Nova Scotia suggests that all of these isolates may be capable of infecting other hosts than the one that they were originally isolated from. This suggestion is supported by challenge experiments that used the Atlantic cod (Cod02ac) and the haddock (Had02ac2) isolates to challenge juvenile Atlantic cod, haddock and Atlantic halibut. Both the Atlantic cod and haddock isolates were able to cause disease in both species, but neither caused disease in Atlantic halibut (Cusack 2002). The current terminology used to designate NNV strains is based on the host (Van Regenmortel et al. 2000), and this may create the impression that the virus strains are host specific.

Our deduced coat protein sequences are very similar to those of other fish nodaviruses in many respects. For example, they have an $\mathrm{N}$ terminus that is rich in basic amino acids, a feature that is thought to contribute to 
the binding of the genomic RNA to the internal capsid wall (Fisher \& Johnson 1993). They also have a high level of conservation of the non-coding 3 ' portion of RNA2. This region is believed to be necessary for the replication and template recognition of RdRp in alphanodaviruses (Kaesberg et al. 1990).

Reconstructed phylogenetic trees with or without an outgroup produced similar results, placing all of the isolates that we examined within the same monophyletic group, designated ACNNV. The isolate obtained from Atlantic cod in Newfoundland (Cod02ac2) branches earlier in the rooted tree, possibly indicating an ancestral state versus the other North Atlantic isolates. Within this monophyletic group, the haddock isolates from New Brunswick cluster with the New Brunswick winter flounder isolate and the isolate from Atlantic cod in New Hampshire. The low support value of this grouping reflects the presence of some variable nucleotides present also in Atlantic cod isolates from Nova Scotia. This may have been caused by some nucleotide replacements common to isolates of both areas.

Based on our phylogenetic analysis, the isolates within the ACNNV clade seem to have evolved separately from isolates within the most closely related clade, the barfin flounder clade, for some time. Both the ACNNV clade and the barfin flounder clade consist of NNV isolates from cold-water species. These isolates are well separated from members of the other clades that have been isolated from hosts collected in more temperate and tropical waters. In contrast to the Atlantic halibut nodavirus sequence from Norway, which is highly similar to BFNNV from Japan (Grotmol et al. 2000), all North Atlantic isolates sequenced to date seem to have evolved separately from the sister group formed by the BFNNV clade some time ago.

Starkey et al. (2001) provided nucleotide sequences for the T4 region of NNV isolated from Atlantic cod and Dover sole in the UK. These sequences are reported to have $>99 \%$ nucleotide homology to the Atlantic halibut nodavirus sequence from Norway, placing them within the barfin flounder clade. Although we did not use these sequences in our phylogenetic analysis, their exclusion will not impact our analysis, as they are essentially identical in sequence to the Atlantic halibut NNV isolate (Accession No. AJ245641).

The assignment of NNV type specimens is based on the level of nucleotide homology, with a $20 \%$ nucleotide difference on RNA2 for alphanodaviruses being the level at which isolates are considered different species (Van Regenmortel 2000). The nucleotide homology between current Betanodaviridae type species ranges from $81 \%$ (SJNNV and TPNNV) to $97 \%$ (RGNNV and JFNNV). With respect to our isolates, the closest match to published NNV sequences is a $93 \%$ nucleotide homology with Atlantic halibut NNV from Norway (Accession No. AJ245641). We suggest that this level of difference, as well as the monophyly of North Atlantic isolates and their clear separation from their sister clade (BFNNV), warrants the establishment of a new type species of NNV. We propose that this species be referred to as Atlantic cod NNV (ACNNV), as Atlantic cod was the first host species from which this virus was isolated (Johnson et al. 2002).

Acknowledgements. The authors thank J. Osborne from $\mathrm{NRC}_{i}$ J. Gautreau, L. Boston, P. Harmon and D. MartinRobichaud from $\mathrm{DFO}_{\text {; }} \mathrm{Dr} \mathrm{D}$. Whelan of the Aquaculture Health Unit of NL; and D. Boyce from the Ocean Science Center, Aquaculture Research and Development Facility, NL; N. King, of GreatBay Aquaculture, Portsmouth, $\mathrm{NH}_{\text {; }} \mathrm{Dr}$ D. Bouchard and Dr C. Giray of MicroTechnologies, Richmond, ME; Dr C. Yason and Dr D. Groman from AVC, Charlottetown, PEI. Sequence data from this paper have been deposited in GenBank, where they are available under the Accession Nos. AY547547 to AY547549. This work was supported by grants from AquaNet (NCE, Canada), Aquaculture Collaborative Research and Development Program (ACRDP, DFO, Canada) and Canadian Biotechnology Strategy Fund (CBS, Canada).

\section{LITERATURE CITED}

Altschul SF, Gish W, Miller W, Myers EW, Lipman DJ (1990) Basic local alignment search tool. J Mol Biol 215:403-410

Barker DE, MacKinnon AM, Boston L, Burt MDB and 6 others (2002) First report of piscine nodavirus infecting wild winter flounder Pleuronectes americanus in Passamaquoddy Bay, New Brunswick, Canada. Dis Aquat Org 49:99-105

Cusack RR, MacKinnon AM, Boston L, Peach R, Groman D (2002) Experimental exposure of juvenile Atlantic cod, haddock and Atlantic halibut to nodavirus isolated from Atlantic cod and haddock and the effects of cross-infectivity. In: Harrington KS (ed) Proc 4th Int Symp Aquatic Animal Health. American Fisheries Society, New Orleans, LA, Corrigenda piii

Dalla Valle L, Zanella L, Patarnello P, Paolucci L, Belvedere P, Colombo L (2000) Development of a sensitive diagnostic assay for fish nervous necrosis virus based on RT-PCR plus nested PCR. J Fish Dis 23:321-327

Felsenstein J (1997) An alternating least squares approach to inferring phylogenies from pairwise distances. Syst Biol 46:101-111

Fisher AJ, Johnson JE (1993) Ordered duplex RNA controls capsid architecture in an icosahedral animal virus. Nature 361:176-179

Grotmol S, Nerland AH, Biering E, Totland GK, Nishizawa T (2000) Characterization of the capsid protein gene from a nodavirus strain affecting the Atlantic halibut Hippoglossus hippoglossus and design of an optimal reversetranscriptase polymerase chain reaction (RT-PCR) detection assay. Dis Aquat Org 39:79-88

Johnson SC, Sperker SA, Leggiadro CT, Groman DB, Griffiths SG, Ritchie RJ, Cook MD, Cusack RR (2002) Identification and characterization of a piscine neuropathy and nodavirus from juvenile Atlantic cod from the Atlantic coast of North America. J Aquat Anim Health 14:124-133

Kaesberg P, Dasgupta R, Sgro JY, Wery JP, Selling BH, Hosur 
MV, Johnson JE (1990) Structural homology among four nodaviruses as deduced by sequencing and X-ray crystallography. J Mol Biol 214:423-435

Mori K, Nakai T, Muroga K, Arimoto M, Mushiake K, Furusawa I (1992) Properties of a new virus belonging to nodaviridae found in larval striped jack (Pseudocaranx dentex) with nervous necrosis. Virology 187:368-371

Munday BL, Kwang J, Moody N (2002) Betanodavirus infections in teleost fish: a review. J Fish Dis 25:127-142

Nishizawa T, Mori K, Nakai T, Furusawa I, Muroga K (1994) Polymerase chain reaction (PCR) amplification of RNA of striped jack nervous necrosis virus (SJNNV). Dis Aquat Org 18:103-107

Nishizawa T, Muroga K, Arimoto M (1996) Failure of the polymerase chain reaction (PCR) method to detect striped jack nervous necrosis virus (SJNNV) in striped jack Pseudocaranx dentex selected as spawners. J Aquat Anim Health 8:332-334

Nishizawa T, Furuhashi M, Nagai T, Nakai T, Muroga K (1997) Genomic classification of fish nodaviruses by molecular phylogenetic analysis of the coat protein gene. Appl Environ Microbiol 63:1633-1636

Page RD (1996) TreeView: an application to display phyloge-

Editorial responsibility: Carey Cunningham, Aberdeen, UK netic trees on personal computers. Comput Appl Biosci 12: 357-358

Schmidt HA, Strimmer K, Vingron M, von Haeseler A (2002) TREE-PUZZLE: maximum-likelihood phylogenetic analysis using quartets and parallel computing. Bioinformatics 18:502-504

Starkey WG, Ireland JH, Muir KF, Jenkins ME, Roy WJ, Richards RH, Ferguson HW (2001) Nodavirus infection in Atlantic cod and Dover sole in the UK. Vet Rec 149:179-181

Thiery R, Arnauld C, Delsert C (1999) Two isolates of sea bass, Dicentrarchus labrax L., nervous necrosis virus with distinct genomes. J Fish Dis 3:201-207

Thompson JD, Gibson TJ, Plewniak F, Jeanmougin F, Higgins DG (1997) The CLUSTAL_X windows interface: flexible strategies for multiple sequence alignment aided by quality analysis tools. Nucleic Acids Res 25:4876-4882

Van Regenmortel MHV, Fauquet CM, Bishop DHL, Barstens EB and 7 others (2000) Virus taxonomy, VIIth report of the ICTV. Academic Press, San Diego, CA

Yoshikoshi K, Inoue K (1990) Viral nervous necrosis in hatchery-reared larvae and juveniles of Japanese parrotfish, Oplegnathus fasciatus (Temminck \& Schlegel). J Fish Dis 13:69-77

Submitted: February 18, 2004; Accepted: September 6, 2004 Proofs received from author(s): November 11, 2004 